\title{
A PCTRAN-BASED INVESTIGATION ON THE EFFECT OF INADVERTENT CONTROL ROD WITHDRAWAL ON THE THERMAL-HYDRAULIC PARAMETERS OF A VVER- 1200 NUCLEAR POWER REACTOR
}

\author{
Abid Hossain Khan ${ }^{1 *}$, Md Shafiqul Islam ${ }^{2}$ \\ ${ }^{1}$ Department of Industrial and Production Engineering, Jashore University of Science and Technology, Jashore-7408, Bangladesh \\ ${ }^{2}$ Department of Nuclear Engineering, University of Dhaka, Dhaka-1000, Bangladesh \\ *Corresponding Author E-Mail: khanabidhossain@gmail.com
}

This is an open access article distributed under the Creative Commons Attribution License, which permits unrestricted use, distribution, and reproduction in any medium, provided the original work is properly cited.

\section{ARTICLE DETAILS}

\section{Article History:}

Received 5 July 2019

Accepted 16 August 2019

Available online 10 October 2019

\section{ABSTRACT}

In this work, the effect of inadvertent control rod withdrawal on the thermal-hydraulic parameters of VVER-1200 type nuclear power reactor has been investigated. Personal Computer Transient Analyzer (PCTRAN) has been used to simulate the transient responses associated with the situation. An attempt has been made to find out the maximum amount of positive reactivity that may be inserted instantaneously without causing serious damage to any of the essential reactor components. Four instantaneous positive reactivity insertion case studies have been performed in the range of $2.5-10 \% \Delta \mathrm{k} / \mathrm{k}$ in order to identify the limiting condition for ensuring safety of the nuclear facility. Results show that for all the cases, prompt criticality is observed due to positive reactivity insertion higher than $0.66 \% \Delta \mathrm{k} / \mathrm{k}$. For positive reactivity insertion up to $7.5 \% \Delta \mathrm{k} / \mathrm{k}$, the maximum core thermal power is observed to be less than $160 \%$ of the rated core thermal power. The peak cladding temperature is observed to be less than $800^{\circ} \mathrm{C}$ with no clad failure. However, for $10 \% \Delta \mathrm{k} / \mathrm{k}$ reactivity insertion, core thermal power has been observed to reach nearly $360 \%$ of the rated core thermal power. Also, a $76 \%$ probability of cladding failure is recorded due to peak cladding temperature reaching nearly $1400^{\circ} \mathrm{C}$. To identify the maximum limit of instantaneous positive reactivity insertion, a "Factor of Safety" based analysis has been conducted. Results from the analysis reveal that maximum limit is around $8.8 \% \Delta \mathrm{k} / \mathrm{k}$. This finding is supported by the results from further simulations.

\section{KEYWORDS}

Cladding Failure, Core Thermal Power, Positive Reactivity Insertion, Transient Response, VVER-1200.

\section{INTRODUCTION}

Nuclear power plants are base-load power station with steady but massive power output compared to its size and fuel consumption. Also, it is sometimes argued to be one of the clean energy sources with very low Carbon-di-oxide emission [1]. However, there is a concern among the mass people regarding the potential hazards associated with an accident in a nuclear power plant. The mindset of the common people has been highly influenced by the accidents in recent times such as Three Mile Island (1979), Chernobyl (1986), and Fukushima nuclear accident (2011) and many other small ones. Chernobyl nuclear accident in 1986 shifted the view of people all over the world towards nuclear energy to a hundredeighty degrees. The accident has caused death of around 31 people within a few days [2]. The people living near the accident site have been exposed to radioactive materials, the amount of which could not be measured correctly due to technical limitations [3]. Long-term exposure to radioactive materials has caused carcinoma among thousands of people. Although most of the patients have suffered from Thyroid Cancer [4-6], other cases such as Acute Myeloid Leukemia, Prostate and Skin Cancer have also been reported [7]. The memory of Fukushima Daiichi nuclear accident in 2011 is still fresh among the mindset of people across the globe. While Fukushima Daiichi accident was caused mostly by natural calamity, the lack of safety features can't be overlooked [8]. The accident has caused large-scale radioactive contamination both in seawater $[9,10]$ and soil [11-13]. This contamination is believed be responsible for Thyroid cancer of Japanese people living near the accident site, mostly the young ones $[14,15]$. In case of Three Mile Island accident in 1979, the real scenario is unclear till date. However, researchers believe that there exists an association between the accident and Thyroid Cancer among people living nearby, though it is hard to establish the claim [16]. One thing that is common for all these accidents is that they have all created panic and psychological trauma in the minds of children and adults [17]. Due to these accidents with long-term consequences, a portion of the worldwide population has become very adverse towards nuclear energy.

In order to ensure safety from possible radiation release into the environment, International Atomic Energy Agency (IAEA) has established safety fundamentals that all the member States should abide by [18]. The Gen-III and III+ nuclear power plants constructed and under construction are all designed based on lessons learned from the three severe accidents so that they would be able to ensure maximum human safety and environment. However, the fear of accident and hazard is still prevalent among common people in many countries. Still many, due to lack of proper knowledge, perception are of the belief that there is always a possibility of radiation hazard near a nuclear facility with or without an accident [19]. This concern has led to a declined rate of establishment of nuclear facilities in many countries. However, with proper counseling and knowledge sharing, the perception of the people may be changed from opposing to favorable $[20,21]$. The improved designs of Gen-III and III+ nuclear power plants are sufficient enough to respond to any Design or Beyond Design Basis Accident; like Chernobyl, Three Mile Island or Fukushima. In the worst case scenario, the evacuation perimeter needs to be not more than 800 meters while for the Gen-II reactors, it may be required up to $30 \mathrm{~km}$ depending on country as well as site specific [18].

VVER-1200 is one of the Gen-III+ pressurized water type nuclear reactors with increased safety measures compared to previous models. Primarily, it has five levels of engineering safety barriers in order to prevent radiation into the environment. It has also enhanced passive safety features that are designed to work for a prolong station blackout (SBO) or interruption in cooling water supply to the reactor core. The multiple passive safety systems could be operated for about 72 hours in case of 
station blackout. The reactor core will be flooded with cooling water flowing by gravity/spring/compressed gas action. If severe accident occurs, modern core catcher will be housed of molten materials that will prevent contamination of soil, water or environment [22]. As a result, it is highly unlikely that the environment will be affected by a design or beyond design basis accident in a nuclear power plant of this type. However, it is necessary to conduct pre-estimation the risks that may be associated with an accident in a nuclear power plant in order to ensure nuclear and radiological emergency preparedness and prevention of serious health hazard of the workers and employees.

Numerous studies have been conducted over the years on the response of the nuclear plant safety systems during normal and accidental situations. While there are many methods of conducting studies like these, numerical investigation is one of the safest options. As a result, researchers have been using different simulation tools to analyze the transient behavior of a nuclear power plant. Some of the simulation tools of code deal only with reactor kinetics and some with nuclear thermal hydraulics while some deal with both. Gaston et al. utilized the MOOSE (Multiphysics Object Oriented Simulation Environment) framework for simulation of full core of a nuclear reactor [23]. Wu et al. developed a new CAD-based Monte Carlo program named SuperMC for integrated simulation of nuclear reactor systems [24]. Hamilton et al. evaluated the performance of multiphysics coupling algorithms for nuclear reactor simulation [25]. Pawluczyk et al. investigated loss of coolant accident in a Pressurized Water Reactor (PWR) using RELAP5 and Cathare-2 thermal hydraulic codes [26]. Delchini et al. conducted simulations of single and two-phase shock tubes and gravity driven wave problems using RELAP7 [27]. Personal Computer Transient Analyzer (PCTRAN) is such a simulation tool for transient analysis of nuclear power reactors. This tool has been used by many researchers for various accident analyses. Bezrukov et al. studied different reactor core re-flooding cases for VVER reactors during a loss of coolant accident [28]. Fyza et al. analyzed the thermal hydraulic parameters of a VVER-1200 nuclear power plant during a loss of coolant accident accompanied by loss of external power supply [29]. Inadvertent control rod withdrawal is one of the possible causes of severe accident in a nuclear facility, as in case of Chernobyl accident [30]. Numerous studies have been conducted to evaluate the effect of uncontrolled fast withdrawal of control rods on the reactor transient. Ibrahim et al. conducted simulations for the safety and transient analysis of a PWR using the Personal Computer Transient Analyzer [31]. Molla demonstrated the use of PCTRAN as simulation tool for safety and transient analysis of a PWR [32]. Suthar and Kumar have shown PCTRAN as an analyzer for critical accident scenario [33]. All these studies have focused of one or more accidental scenarios that may hamper the safety of a nuclear power plant. However, a comparative study on the effect of varying amount of reactivity insertions on the thermal-hydraulic parameters of a nuclear power plant is yet to be conducted. Moreover, studies on inadvertent control rod withdrawal specifically for VVER-1200 type nuclear reactor are very few. Also, a limiting value for reactivity insertion at a time is not clearly mentioned in the available literature.

In this work, the effect of inadvertent control rod withdrawal on the thermal-hydraulic parameters of VVER-1200 type nuclear power plant has been conducted with the help of PCTRAN simulation tool. The amount of positive reactivity insertion at a time has been varied in the range of 2.5 $10 \% \Delta \mathrm{k} / \mathrm{k}$ with a step size of $2.5 \% \Delta \mathrm{k} / \mathrm{k}$. The objective of the study to identify whether the plant safety systems are capable of preventing degradation of reactor core components such as fuel rod, cladding, pressure vessel, etc. during scenarios like these or not. The work has also attempted to find the maximum allowable amount of positive reactivity that may be inserted instantaneously without causing damage to the reactor components.

\section{METHODOLOGY}

In a nuclear power reactor, electricity is produced by converting nuclear energy into mechanical energy that is used to turn the shaft of a generator. The source of this nuclear energy is due to nuclear fission reaction. The power developed in a nuclear power reactor is proportional to the amount of nuclear fission reaction occurring per unit time. The typical fission chain reaction in a Uranium-235 based nuclear power reactor is given in equation (1),

${ }_{92}^{235} U+{ }_{0}^{1} n \rightarrow{ }_{Z_{1}}^{A_{1}} X_{1}+{ }_{Z_{2}}^{A_{2}} X_{2}+\eta \cdot{ }_{0}^{1} n+$ Energy

Here $X_{1}$ and $X_{2}$ are the products of the chain reaction. The atomic number and mass number of $X_{1}$ are $Z_{1}$ and $A_{1}$ respectively and the atomic number and mass number of $\mathrm{X}_{2}$ are $\mathrm{Z}_{2}$ and $\mathrm{A}_{2}$ respectively. The excess neutron obtained from each fission reaction is the one that sustains the chain reaction. However, not all the neutrons produced from a fission reaction will be available for next fission reaction due to leaks, absorption by nonfissionable elements and fission cross-section of the fissile material. The increase or decrease in neutron population and thus neutron flux inside a finite reactor may be measured by effective neutron multiplication factor, $k_{\text {eff }}$ which is given by,

$k_{\text {eff }}=\frac{\text { Rate of neutron production }}{\text { Rate of neutron absorption }+ \text { rate of leakage }}$

This effective neutron multiplication factor for a thermal reactor is dependent on six factors. The relationship between the factors and effective neutron multiplication factor is given by the six-factor formula [34] as shown in equation (3);

$k_{\text {eff }}=\varepsilon \cdot p \cdot f \cdot \eta \cdot L_{F} \cdot L_{T}$

Here $\varepsilon$ is fast fission factor, $p$ is resonance escape probability, $f$ is thermal utilization factor, $\eta$ is neutron reproduction factor, $L_{F}$ is fast neutron nonleakage factor and $L_{T}$ is thermal neutron non-leakage factor. A reactor is considered to be in steady-state condition i.e. critical when $k_{\text {eff }}=1$. If $k_{\text {eff }}$ is greater than 1 , the reactor is considered to be supercritical and if $k_{\text {eff }}$ is less than 1 , the reactor is considered to be sub-critical. Sometimes it is more convenient to use reactivity of a reactor, $\rho$ rather than effective neutron multiplication factor, $k_{\text {eff }}$ from an operator's point of view. The reactivity $(\rho)$ of a reactor at any given time is denoted by equation (4);

$\rho=\frac{k_{e f f}-1}{k_{e f f}}=\frac{\Delta k_{e f f}}{k_{e f f}}$

A reactor is critical if $\rho=0$. The reactor is sub-critical when $\rho<0$ and supercritical when $\rho>0$.Reactivity is a unit less quantity. However, different units are used for reactivity such as $\% \Delta \mathrm{k} / \mathrm{k}, \mathrm{pcm}$, etc. A reactor becomes prompt critical i.e. in an uncontrollable state when a certain amount of positive reactivity is inserted in a reactor at a time. This reactivity is,

$\rho=\beta$

Here $\beta$ is the fraction of delayed neutron present at a given time. For Uranium-235 fuelled reactors, $\beta=0.0066=0.66 \%$. Therefore, rapid insertion of positive reactivity may lead to severe accident.

In a reactor system, there are two groups of neutrons; prompt neutrons and delayed neutrons. The prompt neutrons are instantaneously emitted from fission reaction while the delayed neutrons are emitted from the decay of the fission products. Since there are multiple radioactive fission products with different half-lives and concentration, it is somewhat convenient to adopt a one-group approximation for all the delayed neutrons. The equations in one-group approximation for reactor kinetics are given by [34],

$\frac{d n}{d t}=\left(\frac{\rho-\beta}{A}\right) n+\lambda C+S$

$\frac{d C}{d t}=\frac{\beta}{A} n-\lambda C$

Here $n$ is the number of neutrons per unit volume, $\lambda$ is the effective decay constant for all the precursors of delayed neutrons, $C$ is the concentration of all the precursors, $S$ is the rate of neutron generation from source and $A$ is the average neutron generation time given by equation (8);

$A=\frac{l}{k_{e f f}}$

Here, $l$ is the average neutron lifetime. The neutron flux, $\varphi$ inside a nuclear reactor at any time may be obtained from the one-group neutron diffusion equation [34], which is given by equation (9);

$\frac{d \varphi}{d t}=\vartheta \frac{d n}{d t}=\vartheta\left(D \nabla^{2} \varphi-\sum_{a} \varphi+S\right)$

Here $\mathrm{D}$ is the diffusion coefficient and $\sum_{a}$ is the macroscopic absorption cross-section of the medium. The equation may be applied for neutrons of all energy. However, for a thermal reactor, fission reaction is mostly initiated by thermal neutrons having energy nearly $0.0253 \mathrm{eV}$. The power developed by a thermal nuclear reactor may be given by equation (10) [35];

$P=E \varphi_{t h} V \sum_{f}$

Here $P$ is the power developed by a reactor, $\varphi_{t h}$ is the average neutron flux for thermal neutron, $E$ is the amount of energy released per fission reaction, $V$ is the volume of the reactor core and $\sum_{f}$ is the fission crosssection of the fuel material. Since power generated in a reactor at a specific 
time is directly proportional to the neutron flux inside the reactor and thus the thermal neutron population at a given time, the amount of positive reactivity inserted or removed from the reactor core controls the power output of a reactor. Inadvertent withdrawal of control road suddenly increases positive reactivity inside the reactor core and thus increases reactor power rapidly. As a result, the reactor may become prompt critical, as stated earlier.

Since the rate of heat generation is ideally proportional to the volume of the fuel, it is far more convenient to use volumetric heat generation rate rather than the overall rate of heat generation. The average value of volumetric heat generation may be given by equation (11) [36],

$q^{\prime \prime \prime}=\frac{P}{V}$

Here $q^{\prime \prime \prime}$ is volumetric heat generation. The thermal energy developed in the fuel elements are continuously transferred to the primary coolant in the form of heat. The temperature drop across the fuel element is given by equation (12) [36];

$T_{c}-T_{f s}=\frac{q^{\prime \prime \prime} r_{f}^{2}}{4 K_{F}}$

Here, $T_{c}$ is fuel centerline temperature, $T_{f s}$ is temperature at fuel surface, $r_{f}$ is radius of fuel pellet and $K_{F}$ is thermal conductivity of fuel. Similarly, the temperature drop across the gas gap is given by equation (13) [36];

$T_{f s}-T_{\text {clad }, \text { in }} \cong \frac{q^{\prime \prime \prime} r_{F} t_{G}}{2 K_{G}}$

Here, $T_{\text {clad }, \text { in }}$ temperature of inner surface of cladding, $t_{G}$ is gas gap thickness and $K_{G}$ is thermal conductivity of gas. Also, the temperature drop across the cladding is given by equation (14) [36];

$T_{\text {clad,in }}-T_{\text {clad,out }} \cong \frac{q^{\prime \prime \prime} r_{F} t_{C}}{2 K_{C}}$

Here, $T_{\text {clad,out }}$ temperature of inner surface of cladding, $t_{c}$ is cladding thickness and $K_{C}$ is thermal conductivity of cladding material. Finally, heat transfer from cladding surface to coolant may be described by Newton's law of cooling, which may be expressed as equation (15).

$T_{\text {clad,out }}-T_{\infty} \cong \frac{q^{\prime \prime \prime}}{2 \pi h_{\infty}\left(r_{F}+t_{C}\right)}$

Here, $T_{\infty}$ and $h_{\infty}$ are bulk coolant temperature and convection heat transfer coefficient respectively. Since inadvertent control rod withdrawal will essentially increase the power developed in the reactor, the temperatures at different parts and components of the reactor will increase. If the values exceed the safety limits, the reactor components are bound to be damaged.

In this work, the effect of inadvertent withdrawal of control rod on the thermal-hydraulic parameters of a VVER-1200 model nuclear power plant has been studied. Personal Computer Transient Analyzer (PCTRAN) has been used to simulate the transient behavior of the nuclear power plant parameters. PCTRAN-Personal Transient Computer Analyzer is PC based software developed by Micro Simulation Technology Inc., USA and used for reactor transient and accident analysis simulation for various models of reactor. There are different versions of the simulator, each designed for a specific type of reactor. In this study, the PCTRAN VVER-1200 module has been used. The PCTRAN VVER-1200 console has been presented in Fig.1.

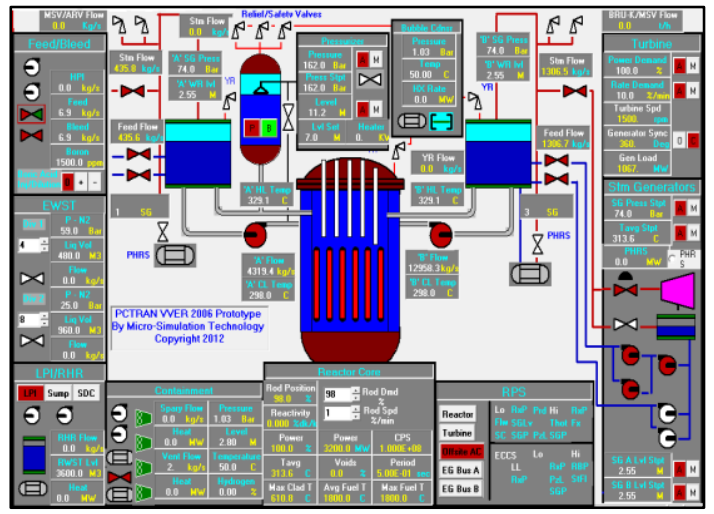

Figure 1: PCTRAN consol for VVER-1200 nuclear power plant

Before coming to any conclusion from the results of a simulation tool, it is first necessary to validate the results with real-life experimental data.
Since VVER-1200 is the latest model of the VVER reactor series, most of the nuclear power plant based on this reactor is still under construction. Therefore, real-life data for these power plants are yet not available for all accidental scenarios. However, VVER-1200 is a modification of VVER1000 with enhanced safety features. The results obtained from PCTRAN VVER-1000 simulator for inadvertent control rod withdrawal have been validated in available literature by comparing with experimental results. A comparison between Final Safety Assessment Report (FSAR) results for a VVER-1000 based nuclear power plant and results obtained from PCTRAN VVER-1000 simulator tool is presented in Fig. 2 [12]. From Fig. 2 it may be observed that the experimental values are slightly higher than the values obtained from PCTRAN. However, the two results have similar trend and PCTRAN has anticipated that transient response of the plant quite accurately. It may be noted that in the experimental report, the time count was initiated from the time control rod was withdrawn inadvertently. However, during PCTRAN simulation, the researchers have initiated the inadvertent control rod withdrawal even 1 second after the beginning of the time count. As a result, the response curve of PCTRAN has experienced a 1 second delay in each response.
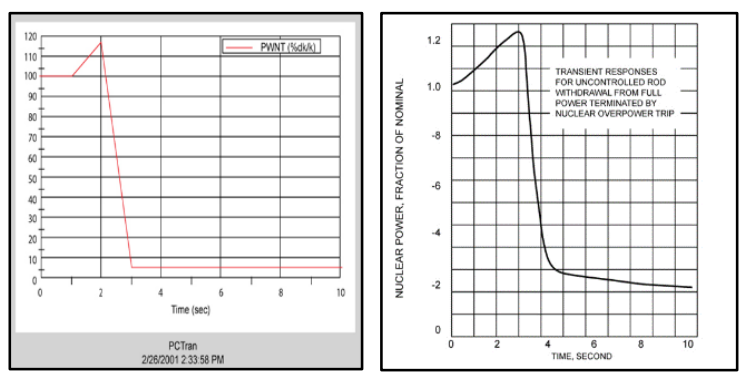

Figure 2: Comparison between PCTRAN simulation results and FSAR experimental results for uncontrolled fast rod withdrawal [32].

Since the results obtained from VVER-1000 simulator is somewhat similar to the real-life experimental results, it may be assumed that the results obtained from PCTRAN simulator are reliable. Since VVER-1000 and VVER-1200 are very similar in design, it may be assumed that PCTRAN VVER-1200 simulator should also generate results close to real-life situations. However, it should be pointed out that results from PCTRAN may sometimes underestimate the actual situation. Therefore, final conclusion should be drawn not only on the basis of PCTRAN results alone but also on the basis of further experiments. Nonetheless, the results obtained from PCTRAN may be used to design the subsequent experiments with necessary safety precautions and also to get an idea of what the results of the experiments might be.

In this study, PCTRAN VVER-1200 has been used to generate the transient response data for inadvertent control rod withdrawal scenario. Positive reactivity has been inserted inside the VVER- 1200 reactor core by rapidly removing control rods. Positive reactivity more than $0.66 \% \Delta \mathrm{k} / \mathrm{k}$ has been inserted in all cases in order to make the reactor prompt critical, which may lead to a severe accident scenario. It has also been assumed that the station's AC power supply from outside source has been completely cutoff in order to observe the effectiveness of the passive safety systems. Four different positive reactivity insertions have been investigated in this work. They are $2.5 \%, 5 \%, 7.5 \%$ and $10 \% \Delta \mathrm{k} / \mathrm{k}$. The reactivity has been inserted after a 10 seconds delay from the initiation of the transient simulation so that obtained response may be compared to the normal operation condition. The thermal-hydraulic parameters of VVER-1200 model reactor during normal operating conditions are given in Table 1.

Table 1: Thermal-hydraulic parameters of VVER-1200 model nuclear reactor

\begin{tabular}{|l|l|}
\hline Plant Parameter & Quantity \\
\hline Core Thermal Power & $3200 \mathrm{MW}_{\text {th }}$ \\
\hline Pressure inside Reactor Core Structure (RCS) & $162.0 \mathrm{bar}$ \\
\hline Average Primary Coolant Temperature & $313^{\circ} \mathrm{C}$ \\
\hline Average Primary Coolant Flow Rate & $17277.7 \mathrm{~kg} / \mathrm{s}$ \\
\hline Maximum Cladding Temperature & $610.8^{\circ} \mathrm{C}$ \\
\hline Maximum Fuel Temperature & $1800^{\circ} \mathrm{C}$ \\
\hline Departure from Nucleate Boiling Ratio (DNBR) & 1.5 \\
\hline
\end{tabular}

In this study, a demo version of PCTRAN VVER-1200 has been used for generating the simulation results. The only limitation of the demo version is that it can give transient response data for only for 300 seconds time. Nevertheless, most of the Gen III+ reactor safety systems start operating 
within 50 seconds from the initiation of the accident. As a result, the plant comes under control within 100 seconds time provided that all the plant safety systems are fully operational. In this study, it has been assumed that none of the safety systems are dysfunctional. Therefore, 300 seconds time limit should be sufficient for this study.

The simulation results are then analyzed to evaluate whether the plant has ensured the acceptance criterion [37, 38] of Design Basis Accidents (DBAs), which are:

- The cladding temperature should not exceed $1480^{\circ} \mathrm{C}$,

- There should be no fuel meltdown, thus fuel temperature should not exceed $2800^{\circ} \mathrm{C}$,

- The pressure inside the reactor pressure vessel should not exceed $110 \%$ of the design value for Anticipated Transient with Scram.

If some or all of the above criterions are not met, it may be considered that the reactor core will undergo severe damage leading to severe accident situation. In this work, different values of instantaneous positive reactivity insertions have been considered in order to identify which one may result in damage of the reactor components and lead to severe accident. Furthermore, additional analysis has been conducted to find the safety margin for positive reactivity insertion.

\section{RESULTS AND DISCUSSION}

In order to understand the changing pattern of the thermal hydraulic parameters of the nuclear reactor, it is necessary to investigate the transient response of the plant in order to manage the situation. Table 2 presents the transient response of the plant safety systems for different positive reactivity insertion cases.

From Table 2, it may be observed that the for $2.5 \%, 5.0 \%$ and $7.5 \% \Delta \mathrm{k} / \mathrm{k}$ instantaneous positive reactivity insertions through inadvertent control rod withdrawal, the sequences of transient response of the plant safety systems were almost the same. In all the three cases, SCRAM was initiated along with turbine trip, followed by Steam Generator Safety Relief Valve (SRV) opening to reduce steam pressure and closing afterwards. However, for higher value of reactivity insertion, the response time has somewhat reduced for all the cases. For $2.5 \%$ and $5.0 \% \Delta \mathrm{k} / \mathrm{k}$ positive reactivity insertion, SCRAM, turbine steam bypassing and turbine trip are all initiated after 14.5 seconds time delay from the reactivity insertion. For $7.5 \% \Delta \mathrm{k} / \mathrm{k}$ reactivity insertion, the time delay for the same was 14.0 seconds since the higher power surge has triggered the safety systems earlier. For $10 \% \Delta \mathrm{k} / \mathrm{k}$ reactivity insertion, turbine steam bypassing is initiated one second prior to SCRAM and turbine trip at 13.0 seconds. This variation may have been caused by the rapid increase in core thermal power, which may have suddenly increased the rate of steam generation. As a result, steam bypassing is initiated earlier than SCRAM.

Table 2: Transient report for different positive reactivity insertions

\begin{tabular}{|c|c|c|c|c|}
\hline \multirow[b]{2}{*}{ Event } & \multicolumn{4}{|c|}{ Time (sec) } \\
\hline & $\begin{array}{l}2.5 \% \\
\Delta \mathrm{k} / \mathrm{k}\end{array}$ & $\begin{array}{l}5.0 \% \\
\Delta \mathrm{k} / \mathrm{k}\end{array}$ & $\begin{array}{l}7.5 \% \\
\Delta \mathrm{k} / \mathrm{k}\end{array}$ & $\begin{array}{c}10.0 \% \\
\Delta \mathrm{k} / \mathrm{k}\end{array}$ \\
\hline $\begin{array}{l}\text { Inadvertent Control Rod } \\
\text { Withdrawal }\end{array}$ & 10.0 & 10.0 & 10.0 & 10.0 \\
\hline $\begin{array}{l}\text { Turbine Bypass Valve (TBV) } \\
\text { Opened }\end{array}$ & 14.5 & 14.5 & 14.0 & 13.0 \\
\hline Reactor SCRAM & 14.5 & 14.5 & 14.0 & 14.0 \\
\hline Turbine Trip & 14.5 & 14.5 & 14.0 & 14.0 \\
\hline 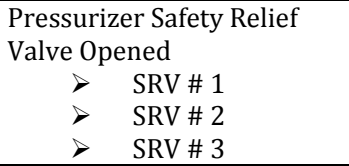 & - & - & - & $\begin{array}{l}15.0 \\
15.5 \\
18.0\end{array}$ \\
\hline 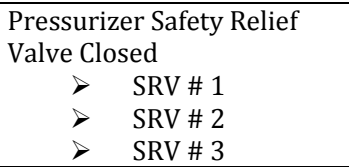 & - & - & - & $\begin{array}{l}23.0 \\
22.5 \\
20.5\end{array}$ \\
\hline $\begin{array}{l}\text { Steam Generator Safety } \\
\text { Relief Valve Opened }\end{array}$ & & & & \\
\hline $\begin{array}{ll}> & \text { SRV \# 1 } \\
> & \text { SRV \# 2 } \\
> & \text { SRV \# 3 } \\
> & \text { SRV \# 4 } \\
\end{array}$ & $\begin{array}{l}25.5 \\
39.5 \\
25.0 \\
57.5 \\
\end{array}$ & $\begin{array}{l}20.5 \\
22.5 \\
23.5 \\
26.0 \\
\end{array}$ & $\begin{array}{l}19.5 \\
20.0 \\
22.0 \\
22.5 \\
\end{array}$ & $\begin{array}{l}16.0 \\
16.0 \\
17.5 \\
17.5 \\
\end{array}$ \\
\hline $\begin{array}{l}\text { Steam Generator Safety } \\
\text { Relief Valve Closed }\end{array}$ & & & & \\
\hline
\end{tabular}

\begin{tabular}{|l|c|c|c|c|}
\hline$>$ SRV \# 1 & 78.5 & 62.5 & 58.5 & 118.5 \\
$>$ SRV \# 2 & 84.0 & 62.5 & 58.5 & 118.5 \\
$>$ SRV \# 3 & 55.5 & 37.5 & 57.5 & 59.5 \\
$>$ SRV \# 4 & 61.0 & 37.5 & 57.5 & 59.5 \\
\hline Containment Spray Started & - & - & - & 197.0 \\
\hline Containment Vent Valve & - & - & - & 197.0 \\
(CVV) Closed & & & & \\
\hline
\end{tabular}

For $2.5 \%, 5.0 \%$ and $7.5 \% \Delta \mathrm{k} / \mathrm{k}$ instantaneous positive reactivity insertions, the time delay of Steam Generator SRV opening has decreased with the increase in the value of reactivity inserted. Also, the time duration for which SRV is kept open has increased with increasing value of reactivity insertion. The only variation is observed for $10.0 \% \Delta \mathrm{k} / \mathrm{k}$ reactivity insertion where the SRV has opened earlier than the former cases, but has closed after a longer time delay. The reason behind this may be the generated thermal energy being significantly higher than the other cases, which required comparatively higher amount of steam relief from the Steam Generator.

An interesting variation observed from Table 2 in the transient report for $10 \% \Delta \mathrm{k} / \mathrm{k}$ reactivity insertion is that Pressurizer Safety Relief Valve has also operated to keep the pressure inside Reactor Pressure Vessel (RPV) within safety limit. This was not required for the former three cases. This indicates that the rapid pressure increase is to be expected for this scenario. Finally, the containment spray system is activated at 197 seconds time in order to avoid pressure buildup inside Reactor Containment Building (RCB). Also, the containment vent valve is closed at the same time. This indicates that there should be a significant increase in reactivity inside the RCB air. The possible causes behind this may be the release of primary coolant from Pressurizer SRVs and/ or possible release of radioactive fission products if somehow cladding failure has occurred.

After investigating the transient reports obtained from PCTRAN for different amount of instantaneous positive reactivity insertions, it is necessary to analyze the effect of the plant response on the reactor thermal hydraulic parameters. Fig.3. shows the change in reactor core thermal power (\%) with time for different reactivity insertion cases. From Fig.3, it may be observed that for all cases, the reactor has experienced a sudden increase in core thermal power. Nonetheless, the core thermal power has come down to less than $5 \%$ of the normal operation value within 50 seconds time due to SCRAM. For an instantaneous positive reactivity insertion of $2.5 \% \Delta \mathrm{k} / \mathrm{k}$, the peak core thermal power is obtained to be around $103 \%$ of the normal operating value. For $5.0 \% \Delta \mathrm{k} / \mathrm{k}$, the peak value is below $115 \%$ while for $7.5 \% \Delta \mathrm{k} / \mathrm{k}$, the peak core thermal power is recorded to be above $150 \%$ of the nominal value. Finally, for $10 \% \Delta \mathrm{k} / \mathrm{k}$ reactivity insertion, core thermal power has suddenly risen to around $360 \%$ of the normal operating value. An exponential trend of increase in peak core thermal power with increase in amount of instantaneous reactivity insertion is observed.
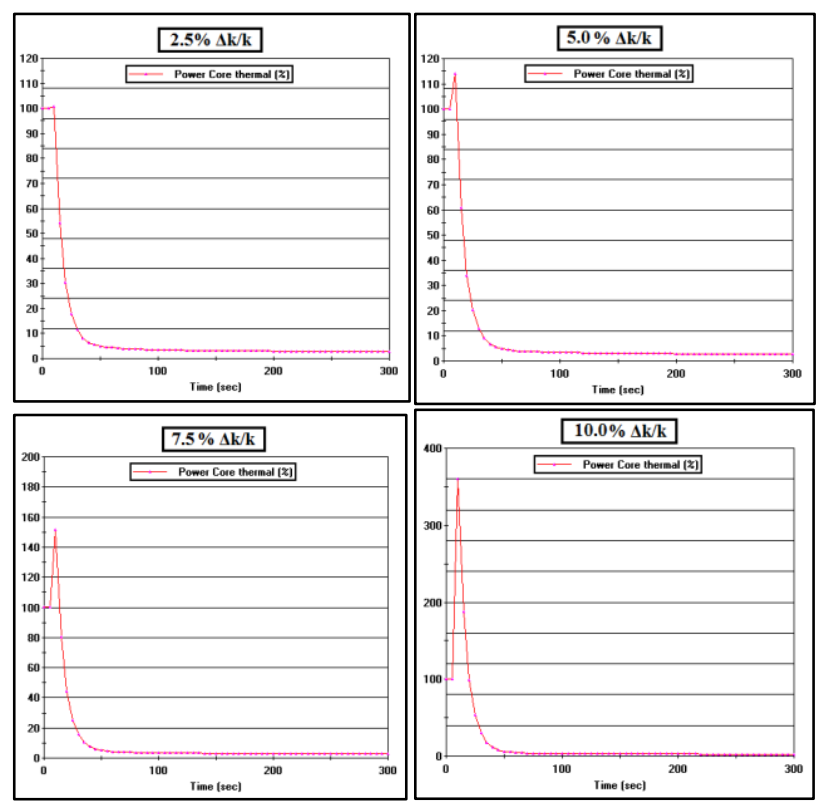

Figure 3: Change in reactor core thermal power (\%) with time for different instantaneous positive reactivity insertions.

The change in temperature of different reactor component with time is shown in Figure 4. From Figure 4, it may be observed that the average temperature of Reactor Core Structure i.e. reactor core and coolant has not 
experienced any significant change in any of the cases considered in this study. However, the peak temperature of both fuel and cladding has increased significantly due to inadvertent control rod withdrawal. For $2.5 \% \Delta \mathrm{k} / \mathrm{k}$, the peak fuel and cladding temperatures are recorded to be around $1820^{\circ} \mathrm{C}$ and $620^{\circ} \mathrm{C}$ respectively. However, for $10 \% \Delta \mathrm{k} / \mathrm{k}$, these values are recorded to be around $2220^{\circ} \mathrm{C}$ and $1400^{\circ} \mathrm{C}$ respectively. While the fuel is still protected from meltdown or serious distortion at this temperature, a probability of $76 \%$ was recorded for cladding failure due to cladding embrittlement and oxidation.

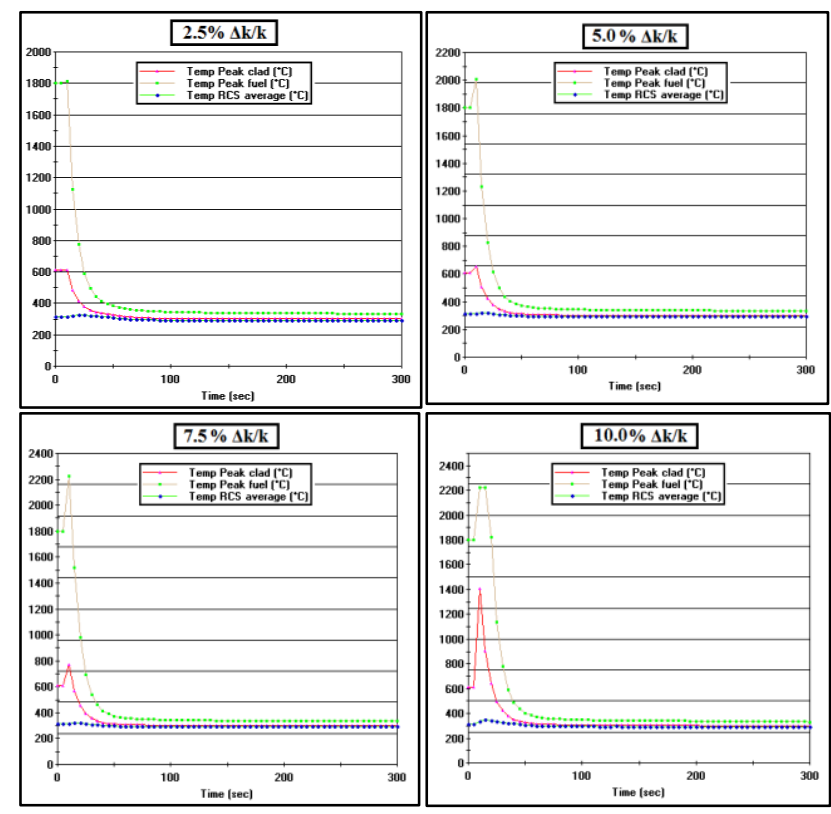

Figure 4: Change in temperature of different reactor components with time for different instantaneous positive reactivity insertions.

The change of DNBR with respect to time for various positive reactivity insertion cases is shown in Fig.5. From Fig.5, it is observed that for $2.5 \%$ and $5.0 \% \Delta \mathrm{k} / \mathrm{k}$ positive reactivity insertions, DNBR is kept at a value near 1.5, which indicates safe operation with no cladding failure. For $7.5 \%$ $\Delta \mathrm{k} / \mathrm{k}$, DNBR has gone slightly below 1 for just 1 second. As a result, the peak cladding temperature was within $800^{\circ} \mathrm{C}$ and no cladding failure was observed. However, for $10.0 \% \Delta \mathrm{k} / \mathrm{k}$ reactivity insertion, DNBR has been reduced significantly to a value below 0.5 , which caused massive increase in heat flux. This may have caused the peak cladding temperature to rise above $1400^{\circ} \mathrm{C}$.
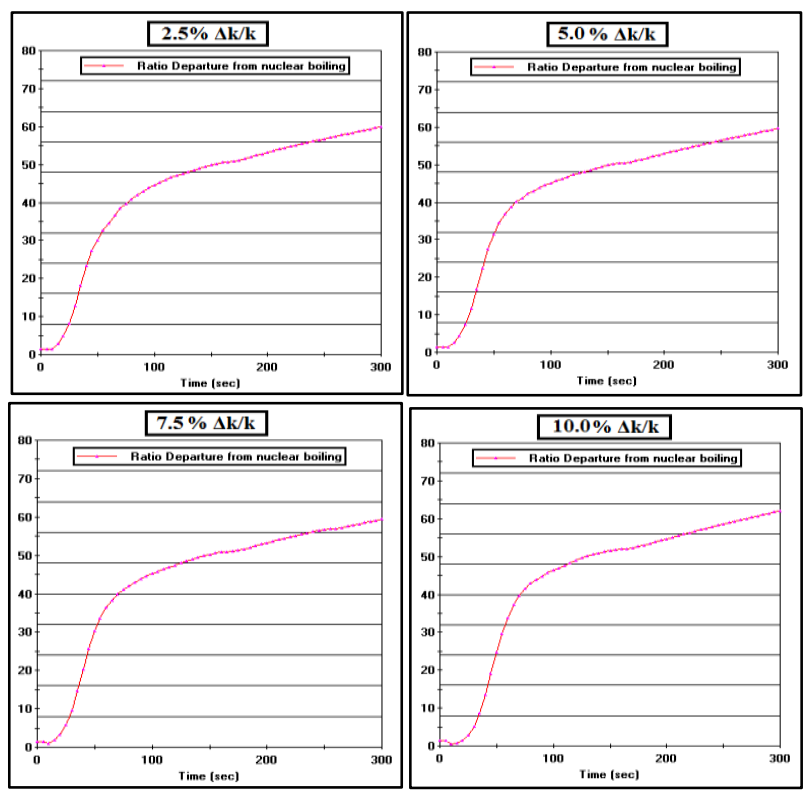

Figure 5: Change in DNBR with time for different instantaneous positive reactivity insertions.

Figure 6. shows the change in pressure inside RPV with time for various conditions. From Figure 6, it may be observed that for $2.5 \%, 5.0 \%$ and $7.5 \% \Delta \mathrm{k} / \mathrm{k}$ positive reactivity insertion cases, the pattern of change is somewhat similar. There is an increase in pressure due to sudden rise in core thermal power, followed by decrease due to SCRAM and steady increase afterwards. In case of $10 \% \Delta \mathrm{k} / \mathrm{k}$ reactivity insertion, however, the decrease in pressure is much greater than the other three cases. This may be due to the activation of SRV of the Pressurizer. For all the three cases, RPV pressure is within the acceptance criteria. Therefore, it may be opined that there is no possibility of pressure vessel failure due to these accidental scenarios.

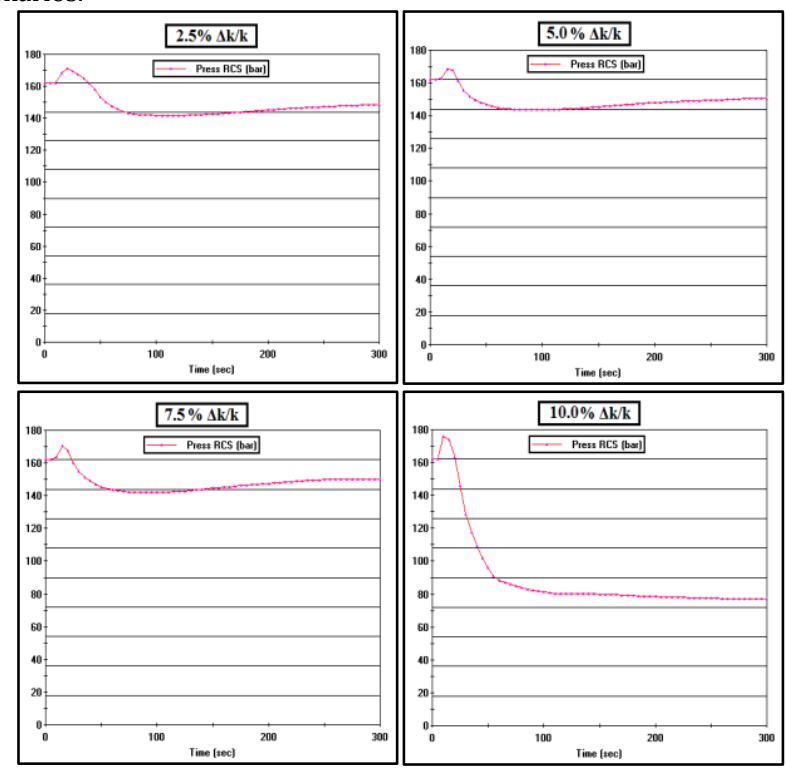

Figure 6: Change in pressure inside RPV with time for different instantaneous positive reactivity insertions.

In order to identify the maximum safe limit of control rod withdrawal and instantaneous positive reactivity insertion, a Factor of Safety (FoS) based analysis is required. Figure 7 shows the change in FoS for both fuel and cladding with respect to the amount of instantaneous positive reactivity insertion. From Figure 7, it may be observed that the FoS curves of fuel and cladding intercept at a point where reactivity is below $8.9 \% \Delta \mathrm{k} / \mathrm{k}$. Therefore, it may be assumed that the maximum limit of reactivity insertion at a time should be around $8.8 \% \Delta \mathrm{k} / \mathrm{k}$.

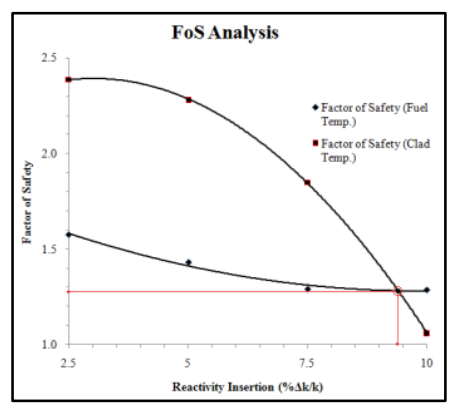

Figure 7: Factor of Safety (FoS) analysis for different reactivity insertion cases.

To validate this result, additional two simulations were conducted using PCTRAN; one in which the reactivity insertion is $8.8 \% \Delta \mathrm{k} / \mathrm{k}$ and another in which reactivity insertion is $9.0 \% \Delta \mathrm{k} / \mathrm{k}$. Figure 8 shows a comparison between the temperature readings obtained from the two cases. From Figure 8, it may be observed that the peak fuel temperature is almost the same for both $8.8 \%$ and $9.0 \% \Delta \mathrm{k} / \mathrm{k}$ positive reactivity insertions. However, the peak cladding temperature is recorded to be below $950^{\circ} \mathrm{C}$ for $8.8 \%$ $\Delta \mathrm{k} / \mathrm{k}$ reactivity insertion while it is above $1000^{\circ} \mathrm{C}$ for $9.0 \% \Delta \mathrm{k} / \mathrm{k}$. Th significance of this difference in temperature may be realized from Figure 9 which presents a comparison between the probabilities of cladding failure between the two cases. From Figure 9, it may be observed that there is the probability of cladding failure is recorded to be $0 \%$ for $8.8 \%$ $\Delta \mathrm{k} / \mathrm{k}$ while it is around $3.5 \%$ for $9.0 \% \Delta \mathrm{k} / \mathrm{k}$ positive reactivity insertion due to inadvertent control rod withdrawal. Therefore, it may be stated that the assumed limiting value is supported by the simulation results.

It is, however, noteworthy that the results obtained from PCTRAN may be slightly lower than the experimental values. Therefore, the maximum safe limit may be slightly lower for real conditions. To account for the uncertainties associated with real life situations, it may be wise to conduct experimental studies with instantaneous positive reactivity insertions lower than the value $8.5 \% \Delta \mathrm{k} / \mathrm{k}$. 


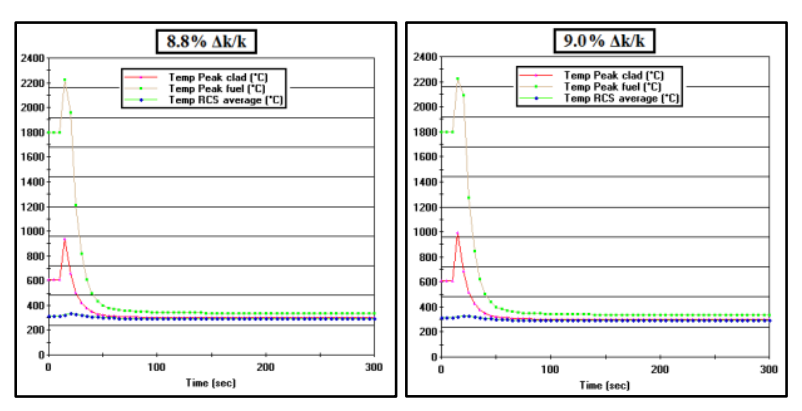

Figure 8: Comparison between temperature readings for $8.8 \%$ and $9.0 \%$ $\Delta \mathrm{k} / \mathrm{k}$ reactivity insertion

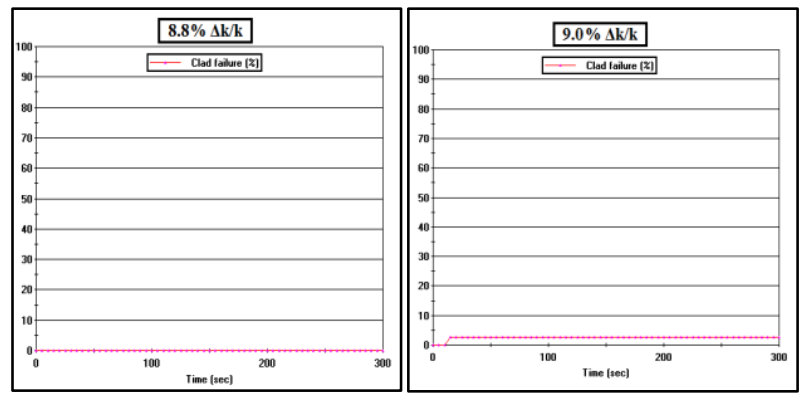

Figure 9: Comparison between cladding failure probabilities for $8.8 \%$ and $9.0 \% \Delta \mathrm{k} / \mathrm{k}$ reactivity insertion

\section{CONCLUSION}

Inadvertent control rod withdrawal may occur multiple times within the lifetime of a reactor in operation due to lack of safety culture among the operators. In this simulation study, the effect of inadvertent control rod withdrawal and thus the effect of rapid insertion of positive reactivity insertion on the thermal-hydraulic parameters of VVER-1200 model nuclear reactor have been investigated. In order to do so, Personal Computer Transient Analyzer (PCTRAN) has been used. With the help of PCTRAN VVER-1200 simulator, the transient behavior of the plant thermal-hydraulic parameters has been observed. It has been assumed that the station has no off-site $\mathrm{AC}$ power supply. Also, the response of the plant safety systems on the verge of prompt criticality has also been investigated by inserting reactivity more than $\beta$, i.e. $0.66 \% \Delta \mathrm{k} / \mathrm{k}$.

Four different case studies have been explored with four different amounts of positive reactivity insertions at a time; $2.5 \% \Delta \mathrm{k} / \mathrm{k}, 5 \% \Delta \mathrm{k} / \mathrm{k}$, $7.5 \% \Delta \mathrm{k} / \mathrm{k}$ and $10 \% \Delta \mathrm{k} / \mathrm{k}$, in order to observe the point up to which the reactor safety systems can manage without causing severe damage to the reactor structure, fuel elements or cladding. Results show that the plant's thermal-hydraulic parameters are well under control as long as positive reactivity insertion is less than or equal to $7.5 \% \Delta \mathrm{k} / \mathrm{k}$. The peak increase in reactor core power is less than $160 \%$ of the nominal value and peak cladding temperature is much lower than the threshold value of $1480^{\circ} \mathrm{C}$ when instantaneous positive reactivity insertion is $7.5 \% \Delta \mathrm{k} / \mathrm{k}$. On the other hand, for $10 \% \Delta \mathrm{k} / \mathrm{k}$ positive reactivity insertion, the core thermal power has reached to a maximum value of around $360 \%$ of the nominal value. Also, the peak cladding temperature has reached to a value higher than $1400^{\circ} \mathrm{C}$, indicating a $76 \%$ probability of cladding failure. Finally, the peak temperature of fuel element has reached to a value higher than $2200^{\circ} \mathrm{C}$, making it vulnerable to distortion and swelling. However, no fuel meltdown is indicated in the simulation results.

A Factor of Safety (FoS) based analysis has been conducted to find the maximum limit of positive reactivity that may be inserted without causing damage to the reactor components. Results from the analysis show that this limiting value is $8.8 \% \Delta \mathrm{k} / \mathrm{k}$. To validate the results of the analysis, further simulations have been conducted by inserting $8.8 \% \Delta \mathrm{k} / \mathrm{k}$ and $9.0 \%$ $\Delta \mathrm{k} / \mathrm{k}$ positive reactivity. The simulation results show that there is no damage to the cladding for $8.8 \% \Delta \mathrm{k} / \mathrm{k}$ reactivity insertion while there is around $3.5 \%$ cladding failure probability for $9.0 \% \Delta \mathrm{k} / \mathrm{k}$ positive reactivity insertion, supporting the results from FoS based analysis. However, in order to account for real-life uncertainties, the suggested limit is $8.5 \%$ $\Delta \mathrm{k} / \mathrm{k}$ for safety of experimental studies.

This study has considered only a combination of inadvertent control rod withdrawal and no off-site AC power supply. The study may be extended to accommodate other events such as failure to bring the control rods down due to mechanical problem. These kinds of hypothetical accidental case studies will, no doubt, ensure operational safety precautions and help in avoiding severe damage to the reactor.

\section{ACKNOWLEDGEMENT}

The authors would like to thank Micro Simulation Technology Inc., USA for developing PCTRAN as a transient analysis tool for VVER-1200 nuclear power reactor.

\section{CONFLICT OF INTEREST}

The authors declare no conflict of interest.

\section{FUNDING SOURCES}

This research did not receive any specific grant from funding agencies in the public, commercial, or not-for-profit sectors.

\section{REFERENCES}

[1] Roth, M.B., Jaramillo, P. 2017. Going nuclear for climate mitigation: An analysis of the cost effectiveness of preserving existing US nuclear power plants as a carbon avoidance strategy. Energy, 131, 67-77.

[2] Highfield, R. 2011. How many died because of the Chernobyl disaster? We don't really know. New Scientist. Available online: https://www.newscientist.com/article/dn20403-how-many-diedbecause-of-the-chernobyl-disaster-we-dont-really-know/

[3] Kortov, V., Ustyantsev, Y. 2013. Chernobyl accident: Causes, consequences and problems of radiation measurements. Radiation Measurements, 55, 12-16.

[4] Alinaghizadeh, H., Wålinder, R., Vingård, E., Tondel, M. 2016. Total cancer incidence in relation to $137 \mathrm{Cs}$ fallout in the most contaminated counties in Sweden after the Chernobyl nuclear power plant accident: a register-based study. BMJ open, 6 (12), e011924.

[5] Efanov, A.A., Brenner, A.V., Bogdanova, T.I., Kelly, L.M., Liu, P., Little, M.P., Wald, A.I., Hatch, M., Zurnadzy, L.Y., Nikiforova, M.N., Drozdovitch, V. 2017. Investigation of the relationship between radiation dose and gene mutations and fusions in post-Chernobyl thyroid cancer. JNCI: Journal of the National Cancer Institute, 110 (4), 371-378.

[6] Handkiewicz-Junak, D., Swierniak, M., Rusinek, D., OczkoWojciechowska, M., Dom, G., Maenhaut, C., Unger, K., Detours, V., Bogdanova, T., Thomas, G., Likhtarov, I. 2016. Gene signature of the postChernobyl papillary thyroid cancer. European journal of nuclear medicine and molecular imaging, 43 (7), 1267-77.

[7] Samoylov, A.S., Bushmanov, A.Y., Udalov, Y.D., Galstyan, I.A., Nugis, V.Y., Kozlova, M.G., Nikitina, V.A., Khvostunov, I.K., Golub, E.V. 2018. Acute Myeloid Leukemia, Prostate And Skin Cancer In Acute Radiation Syndrome Survivor After The 1986 Chernobyl Nuclear Accident: Case Report. Radiation protection dosimetry, 182 (1), 85-9.

[8] Khan, A.H., Hasan, S., Sarkar, M.A.R. 2018. Analysis of Possible Causes of Fukushima Disaster. International Journal of Nuclear and Quantum Engineering, 12 (2), 53-8.

[9] Sanial, V., Buesseler, K.O., Charette, M.A., Nagao, S. 2017. Unexpected source of Fukushima-derived radiocesium to the coastal ocean of Japan. Proceedings of the National Academy of Sciences, 114 (42), 11092-6.

[10] Smith, J.N., Rossi, V., Buesseler, K.O., Cullen, J.T., Cornett, J., Nelson, R., Macdonald, A.M., Robert, M., Kellogg, J. 2017. Recent transport history of Fukushima radioactivity in the Northeast Pacific Ocean. Environmental science \& technology, 51 (18), 10494-502.

[11] Yasunari, T.J., Stohl, A., Hayano, R.S., Burkhart, J.F., Eckhardt, S., Yasunari, T. 2011. Cesium-137 deposition and contamination of Japanese soils due to the Fukushima nuclear accident. Proceedings of the National Academy of Sciences, 108 (49), 19530-4.

[12] Takahashi, J., Tamura, K., Suda, T., Matsumura, R., Onda, Y. 2015. Vertical distribution and temporal changes of 137Cs in soil profiles under various land uses after the Fukushima Dai-ichi Nuclear Power Plant accident. Journal of environmental radioactivity, 139, 351-61.

[13] Mukai, H., Hirose, A., Motai, S., Kikuchi, R., Tanoi, K., Nakanishi, T.M., Yaita, T., Kogure, T. 2016. Cesium adsorption/desorption behavior of clay minerals considering actual contamination conditions in Fukushima. Scientific reports, 6, 21543. 
[14] Tsuda, T., Tokinobu, A., Yamamoto, E., Suzuki, E. 2011. Thyroid cancer detection by ultrasound among residents ages 18 years and younger in Fukushima, Japan: 2011 to 2014. Epidemiology (Cambridge, Mass), 27 (3), 316.

[15] Wakeford, R., Auvinen, A., Gent, R.N., Jacob, P., Kesminiene, A., Laurier, D., Schüz, J., Shore, R., Walsh, L., Zhang, W. 2016. Re: Thyroid cancer among young people in Fukushima. Epidemiology, 27 (3), e20-1.

[16] Goldenberg, D., Russo, M., Houser, K., Crist, H., Derr, J.B., Walter, V., Warrick, J.I., Sheldon, K.E., Broach, J., Bann, D.V. 2017. Altered molecular profile in thyroid cancers from patients affected by the Three Mile Island nuclear accident. The Laryngoscope, 127, S1-9.

[17] Latif, F., Yeatermeyer, J., Horne, Z.D., Beriwal, S. 2015. Psychological impact of nuclear disasters in children and adolescents. Child and Adolescent Psychiatric Clinics, 24 (4), 811-22.

[18] International Atomic Energy Agency (IAEA). 2006. Safety Fundamentals. IAEA Safety Standards Series SF-1.

[19] Chao-jun, L., Chun-ming, Z., Yan, C., Jia-xu, Z., Jia-yun, C. 2013. The study on safety goals and public acceptance of nuclear power. Energy Procedia, 39, 415-22.

[20] Goodfellow, M.J., Dewick, P., Wortley, J., Azapagic, A. 2015. Public perceptions of design options for new nuclear plants in the UK. Process Safety and Environmental Protection, 94, 72-88.

[21] Bisconti, A.S. 2018. Changing public attitudes toward nuclear energy. Progress in Nuclear Energy, 102, 103-13.

[22] Asmolov, V.G., Gusev, I.N., Kazanskiy, V.R., Povarov, V.P., Statsura, D.B. 2017. New generation first-of-the kind unit-VVER-1200 design features. Nuclear Energy and Technology, 3 (4), 260-9.

[23] Gaston, D.R., Permann, C.J., Peterson, J.W., Slaughter, A.E., Andrš, D., Wang, Y., Short, M.P., Perez, D.M., Tonks, M.R., Ortensi, J., Zou, L. 2015. Physics-based multiscale coupling for full core nuclear reactor simulation. Annals of Nuclear Energy, 84, 45-54.

[24] Wu, Y., Song, J., Zheng, H., Sun, G., Hao, L., Long, P., Hu, L. 2015. FDS Team CAD-based Monte Carlo program for integrated simulation of nuclear system SuperMC. Annals of Nuclear Energy, 82, 161-8.

[25] Hamilton, S., Berrill, M., Clarno, K., Pawlowski, R., Toth, A., Kelley, C.T., Evans, T., Philip, B. 2016. An assessment of coupling algorithms for nuclear reactor core physics simulations. Journal of Computational Physics, 311, 241-57.
[26] Pawluczyk, M., Mazgaj, P., Gurgacz, S., Gatkowski, M., Darnowski, P. 2016. Loss of coolant accident in pressurized water reactor. Prediction of a 6-inch cold leg break with Relap5 and Cathare 2. Procedia Engineering, $157,333-40$.

[27] Delchini, M.O., Ragusa, J.C., Berry, R.A. 2017. Simulations of single-and two-phase shock tubes and gravity-driven wave problems with the RELAP-7 nuclear reactor system analysis code. Nuclear Engineering and Design, 319, 106-16.

[28] Bezrukov, Y.A., Schekoldin, V.I., Zaitsev, S.I., Churkin, A.N., Lisenkov, E.A. 2016. A study of different cases of VVER reactor core flooding in a large break loss of coolant accident. EPJ Nuclear Sciences \& Technologies, 2,3 .

[29] Fyza, N., Hossain, A., Sarkar, R. 2019. Analysis of the thermalhydraulic parameters of VVER-1200 due to loss of coolant accident concurrent with loss of offsite power. Energy Procedia, 160, 155-61.

[30] Whittingham, R. 2004. The blame machine: Why human error causes accidents. Routledge.

[31] Ibrahim, S.J., Ewim, D.R., Edeoja, O.A. 2013. Simulation of Safety and Transient Analysis of a Pressurized Water Reactor using the Personal Computer Transient Analyzer. Leonardo Electronic Journal of Practices and Technologies, 22, 93-105.

[32] Mollah, A.S. 2018. PCTRAN: Education Tool for Simulation of Safety and Transient Analysis of a Pressurized Water Reactor. International Journal of Integrated Sciences and Technology, 23, 1-10.

[33] Suthar, A., Kumar, M. 2019. Critical Accident Scenario Analysis of Pressurized Water Reactor. In: ICTEA: International Conference on Thermal Engineering 2019 May 7.

[34] Anglart, H. 2011. Applied Reactor Technology.

[35] US Department of Energy. 1993. DOE Fundamentals Handbook: Nuclear Physics and Reactor Theory.

[36] Duderstadt, J.J., Hamilton, L.J. 1976. Nuclear reactor analysis. Wiley.

[37] International Atomic Energy Agency, Vienna. 2003. Accident Analysis for Nuclear Power Plants with Pressurized Water Reactors, IAEA Safety Report Series, 3.

[38] Advanced Reactors Information System (ARIS). 2006. Status Report 108- VVER-1200 (V-491). 